\title{
A State-of-the-Art Review on Debonding Failures of FRP Laminates Externally Adhered to Concrete
}

\author{
Thomas H.-K. Kang ${ }^{1), *}$, Joe Howell'), Sanghee Kim ${ }^{1)}$, and Dong Joo Lee ${ }^{1)}$
}

(Received April 5, 2012, Accepted May 31, 2012, Published online July 1, 2012)

\begin{abstract}
There is significant concern in the engineering community regarding the safety and effectiveness of fiber-reinforced polymer (FRP) strengthening of RC structures because of the potential for brittle debonding failures. In this paper, previous research programs conducted by other researchers were reviewed in terms of the debonding failure of FRP laminates externally attached to concrete. This review article also discusses the influences on bond strength and failure modes as well as the existing experimental research and developed equations. Based on the review, several important conclusions were re-emphasized, including the finding that the bond transfer strength is proportional to the concrete compressive strength; that there is a certain bond development length that has to be exceeded; and that thinner adhesive layers in fact lower the chances of a concrete-adhesive interface failure. It is also found that there exist uncertainty and inaccuracy in the available models when compared with the experimental data and inconsistency among the models. This demonstrates the need for continuing research and compilation of data on the topic of FRP's bond strength.
\end{abstract}

Keywords: FRP, interfacial bond, bond strength, debonding, bond effective length, concrete, beam.

\section{Introduction}

Much of the concrete infrastructure in the world is aging beyond fifty years, and many of these structures are showing significant deterioration and distress. The use of externally bonded fiber-reinforced polymers (FRP) is becoming a popular means of repair and rehabilitation to extend the service life of such structures. However, existing experimental research shows that the theoretical high ultimate capacity of FRP strengthened reinforced concrete (RC) beams often cannot be achieved because of FRP plate debonding or horizontal cracking and subsequent loss of concrete cover below the reinforcing steel. This significantly reduces the strength enhancement provided by the FRP and can create brittle failures. As a result, there is significant concern in the engineering community regarding the safety and effectiveness of externally bonded FRP strengthening of RC structures.

Debonding failure of FRP reinforced RC beams usually takes place via areas of high stress concentrations. These are usually associated with FRP material termination and the presence/appearance of cracks in the concrete substrate

\footnotetext{
${ }^{1)}$ Department of Architecture and Architectural

Engineering, Seoul National University, Seoul 151-744, Korea.

*Corresponding Author; E-mail: tkang@snu.ac.kr

${ }^{2)}$ School of Civil Engineering and Environmental Science, University of Oklahoma, Norman, OK 73019, USA.

Copyright $($ The Author(s) 2012. This article is published with open access at Springerlink.com
}

(Fig. 1). The path of debonding propagation (see Fig. 2) depends on properties of the substrate concrete, FRP, and interface (adhesive) and follows the path of least resistance. FRP debonding through the concrete substrate was identified as an important failure mode because it occurs at lighter load levels and the failure is very brittle. Early research indicated improper selection of adhesives increases the likelihood of failure, and that the failure behavior was heavily dependent on the existing steel reinforcing ratio and the type of FRP reinforcement. It has also been shown that extending the FRP reinforcement as much as possible toward the supports decreases the potential of debonding, but does not eliminate it. Buyukozturk et al.'s (2004) research revealed that that both failure load and ductility of pre-cracked (in service) RC beams can be significantly increased through the addition of FRP shear strengthening which helps the anchorage of FRP sheets used for flexural strengthening; however, one of the areas lacking an overall understanding is still the interface and bond between the FRP laminates and the concrete substrate. The following sections review the previous research programs on the bond behavior of FRP laminates externally bonded to concrete and the currently available analytical expressions to predict the interface stresses and effective bond lengths.

\section{Previous Research on the Interface Bond of FRP Attached to Concrete}

\subsection{Research by Chajes et al. (1996)}

Chajes et al. (1996) conducted single-lap shear tests to isolate and study the bond strength and force transfer properties of 


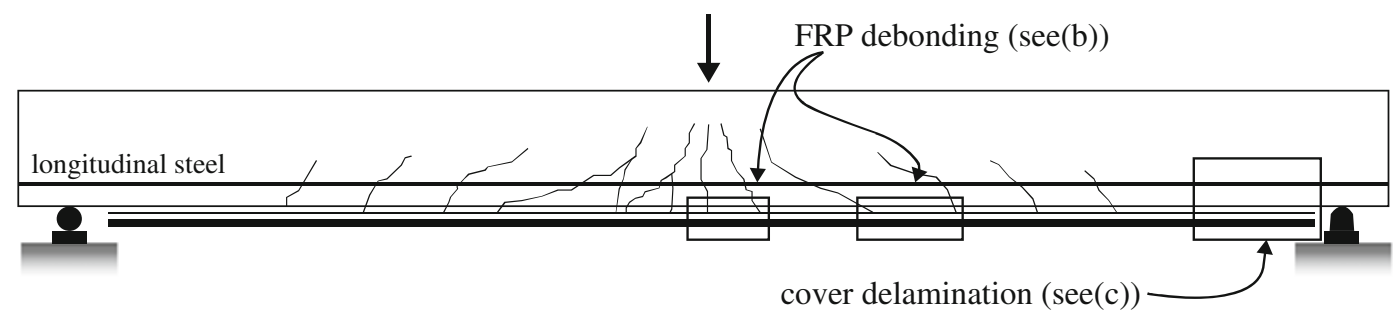

(a) Behavior of flexural member having bonded reinforcement on soffit

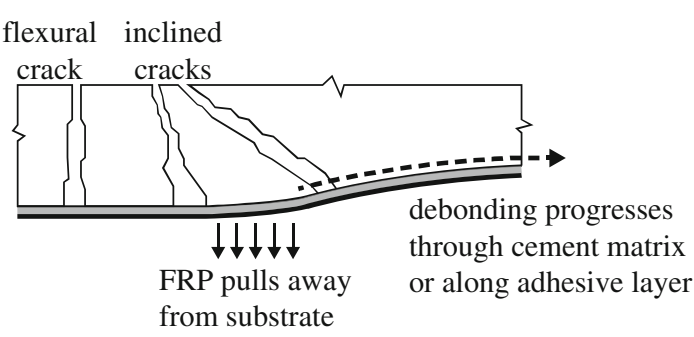

(b) Debonding initiated by flexural and/or shear cracks

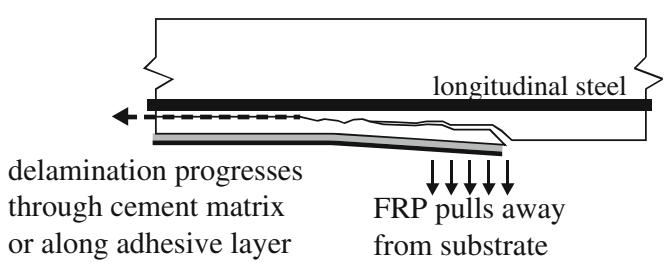

(c) Cover delamination initiated at curtailment of bonded FRP reinforcement

Fig. 1 Debonding and delamination of externally bonded FRP systems (redrawn from ACl 440R.2-08).

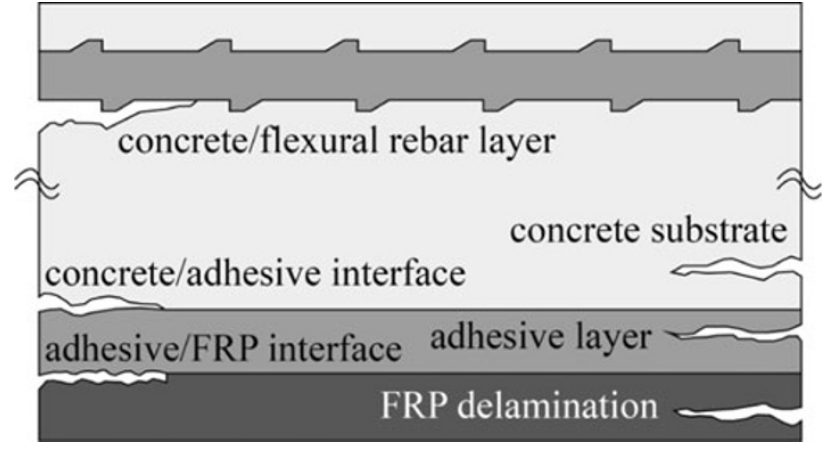

Fig. 2 Paths of debonding propagation.

epoxy bonded composite plates, externally adhered to concrete. The effects of surface preparation, overall concrete strength, and adhesive type were all tested using a constant bond length. Varying bond lengths were then used to study the bond force transfer from plate to concrete. Chajes et al. (1996) contended that the bond between externally bonded fiber plates and the concrete is the single most critical aspect in strengthening concrete structures using such methods.

Initial assumptions and available research indicated the ideal epoxy needed to be stiff enough to transfer the shear force from the concrete to the composite plate while also being tough enough to prevent brittle failure induced by concrete cracking. Chajes et al. (1996) chose to evaluate four different adhesives with stiffnesses ranging from 238 to $5,250 \mathrm{MPa}$ and failure strains from 0.4 to $60 \%$ but with similar tensile strengths.

To evaluate the effect of surface preparation, the three procedures for surface preparation employed were: (a) none, (b) stone wheel grinding to a smooth finish, and (c) wire wheel abrading to slightly expose aggregate, while only one adhesive was used and the concrete mix was kept constant. All specimens were tested under continuously increasing load until failure. For all joints, excluding one adhesive type, failure occurred as a result of concrete shearing directly beneath the bonded surface. There was no debonding or failure through the adhesive. The remaining adhesive type experienced failure through the adhesive itself. The mechanically abraded surface resulted in the highest average failure stress followed by grinding and finally the as-cast preparation. Although the stresses were within $10 \%$, this test demonstrated the influence of surface preparation in strengthening concrete with externally bonded composites.

Concrete blocks were fabricated from the same concrete mix and prepared with mechanical abrasion to test the four adhesive types. The average shear stresses at failure for the three adhesives that exhibited the same failure mode were very similar. This indicates that the final strength of the joint is largely dependent on the concrete strength. The testing also showed that the use of a surface primer, as recommended by epoxy manufacturers, improves the bond by strengthening the concrete surface to be bonded. Since the failure mode of the plate-concrete joint involved shearing the concrete directly below the bond, it was concluded that the ultimate strength is dependent on the concrete strength directly adjacent to the bonded zone, which may not be indicative of the overall strength throughout the member. Variations in water-tocement ratio and aggregate separation throughout the beam can cause inconsistencies in strength properties.

The strain distribution illustrated the rate at which the tensile load was transferred from the composite to the concrete. This transfer is essentially a shear flow and is thus a function of the mechanical properties (i.e., stiffnesses) of the adhesive, composite, and concrete. It was also found that for all bond lengths below failure load, and especially those below service loads, the force transfer can be approximated as uniform. For longer bond lengths, the strain distribution at failure indicates a progressive failure. The strain rate near the loading end tends to slow compared to the remainder of the bond length. This indicates that no load is being transferred to the concrete in that portion of the bond because the concrete has begun to fail. 
Based on their testing, Chajes et al. (1996) drew several conclusions about the bond and force transfer between composites and concrete:

(1) Surface preparation greatly influences the ultimate bond strength. The best bond is achieved by mechanically abrading or sandblasting the concrete surface and then applying an appropriate primer. Roughening and cleaning the composite plate also improves bonding.

(2) Off-the-shelf epoxies can effectively bond composites to concrete without being cost prohibitive. The use of more ductile adhesives leads to weaker bonds but larger failure strains.

(3) There are two main types of failure: shearing of the concrete below the bonded surface and failure of the adhesive-concrete interface.

(4) Since the dominant failure mode is shearing of the concrete beneath the bond, the ultimate strength is proportional to concrete compressive strength $\left(f_{c}^{\prime}\right)$.

(5) The strain distribution in the composite decreases linearly along the bond length, indicating the force transfer is mostly uniform.

(6) There is a bond development length beyond which the load at failure cannot be increased.

Throughout their research, Chajes et al. (1996) used and/or developed several equations to describe the observed behavior. Typically, the ultimate shear stress in concrete at failure $\left(v_{c u}\right)$ was taken to be proportional to $\sqrt{ } f_{c}^{\prime}$. Chajes et al. (1996) found the best fit relation of $\left(v_{c u}=k \sqrt{ } f_{c}^{\prime} \mathrm{MPa}\right.$, where $k=0.925)$.

To describe the shear stress $(\tau)$, the following equation was used:

$$
\tau=\frac{\left(F_{1}-F_{2}\right)}{w \Delta L}
$$

where the terms $F_{1}$ and $F_{2}$ are the forces in the composite material calculated from the elastic modulus and area of the composite at each strain gauge location. The $w$ term denotes the width of the composite and $\Delta L$ is the length between the two gauges.

The average bond resistance, $R(\mathrm{~N} / \mathrm{m})$ is:

$$
R=\frac{\left(F_{1}-F_{2}\right)}{\Delta L}=\tau w .
$$

The ultimate capacity $\left(T_{u}\right)$ of a joint with bond length $L_{b}$ can be approximated by:

$$
\begin{aligned}
& T_{u}=R L_{b} \quad \text { when } L_{b}<\text { the development length }\left(L_{d}\right) \\
& T_{u}=R L_{b} \quad \text { when } L_{b} \geq L_{d}
\end{aligned}
$$

\subsection{Research by Arduini et al. (1997)}

FRP repairs on existing structures have been shown to change the failure mode from ductile to brittle. Factors such as FRP thickness, bonded length, and the addition of shear

reinforcement significantly change the crack distribution and the failure mechanisms. Research by Arduini et al. (1997) aimed at predicting the load-deflection behavior of conventionally reinforced concrete beams reinforced with externally bonded FRP using analytical modeling. Six small scale reinforced concrete test specimens were constructed: two beams were tested without any FRP reinforcement; Beams 3 and 4 had one layer of three parallel plates bonded to the beam soffit; Beams 5 and 6 had two layers of three longitudinal plates along the beam soffit; and Beam 6 also had the addition of a $1.5 \mathrm{~mm}$ thick and $100 \mathrm{~mm}$ wide steel plate wrapped around the end of the CFRP and epoxied to the beam in a U-shape to help anchorage. The mechanical properties of the constituent materials were either obtained experimentally or by assuming common values.

To calculate the bond properties between concrete and adhesive, Arduini et al. (1997) carried out two simple tests of [tension + shear] and [compression + shear] (Fig. 3). Plain concrete prisms were cast along with the beams. After curing, the prisms were cut at inclination angles of $40^{\circ}, 60^{\circ}$, and $70^{\circ}$ for compression and $20^{\circ}, 40^{\circ}$, and $60^{\circ}$ for tension. The pieces were then rejoined with a layer of the same adhesive used to attach the CFRP plates to the beams. Arduini et al. (1997) defined the average shear stress as $\tau=F \sin (\alpha) /(b \times a)$, where $F$ is the ultimate load, $\alpha$ is the cut inclination, and $b$ and $a$ are the lengths of the adhesive surface (see Fig. 3). After using the data from the compression and shear to create the Mohr-Coulomb failure envelope, the ultimate shear strength $\left(\tau_{u}\right)$ was found to be $5 \mathrm{MPa}(0.73 \mathrm{ksi})$.

During the tensile and shear testing, the concrete failed first each time. This test was repeated in a similar method to test the bond properties between the adhesive and the CFRP plate. Testing concluded that the shear strength of the FRPadhesive bond for the epoxy used was approximately three times stronger than the concrete-adhesive interface for concrete with a compressive strength of $33 \mathrm{MPa}$.

All the beams were tested under 4-point bending conditions, and all six showed initial linear elastic behavior followed by a first crack near mid-span. Afterward, the beams experienced a non-linear phase with the development of multiple flexural cracks and a considerable increase in the

(a) Tension+shear

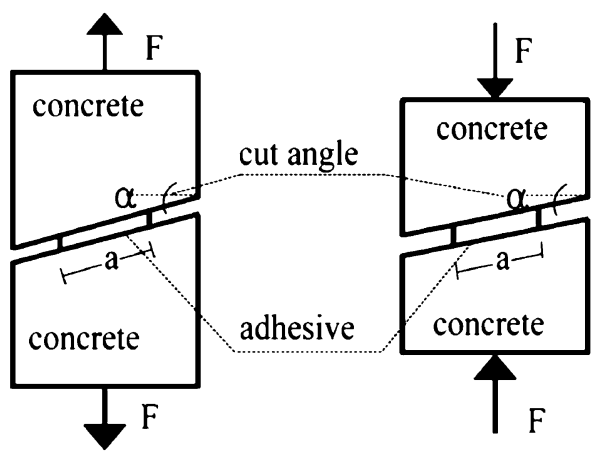

Fig. 3 [tensile + shear] and [compression + shear] concrete-adhesive specimens (redrawn from Arduini et al. 1997). 
CFRP strain. The two unreinforced beams failed according to traditional under-reinforced beam design with concrete crushing well after bottom steel yielding. The two beams with 1 layer of CFRP failed in a brittle concrete cover separation mode. Shear cracks started at the ends of the plates and propagated through the concrete cover parallel to the longitudinal steel. Beam 5 showed considerably more stiffness in the cracked zone with its additional layer but failed at a lower load, again because of concrete cover separation initiating at the end of the CFRP plate. This problem was mitigated by the addition of the steel plate wrapped around the end of the CFRP plate and bonded to the beam.

In addition to testing, Arduini et al. (1997) examined the results of four reinforced concrete beams with nominal dimensions of $300 \times 400 \times 2,500 \mathrm{~mm}$ that were provided by other ongoing research. Beam 1 was left unreinforced while the remaining three beams were strengthened by unidirectional flexible wet-layup CFRP sheets applied to the beam soffits. Beam 2 had only one layer, while Beams 3 and 4 had three layers. Beam 4 also had the addition of a fourth ply wrapped around the beam in a U-shape and epoxied to the beam with the fibers oriented transversely. The plain reinforced concrete beam failed by concrete crushing after steel yielding just like the beam in the Arduini et al. (1997) tests. The second beam, with only one layer of reinforcement, experienced CFRP rupture at mid-span. Beam 3 experienced a concrete cover debonding failure that removed the concrete on the soffit at a load that was approximately 2.5 times higher than the plain section. The final beam reached the highest capacity, indicating the benefit of the transversely wrapped layer of CFRP.

Although the results provided by Arduini et al. (1997) confirmed the strengthening benefits provided by externally bonded FRPs, they also highlighted the existence of sudden brittle failure mechanisms that must be considered.

\subsection{Research by Arduini and Nanni (1997)}

Arduini and Nanni (1997) conducted a parametric study to investigate the effects of FRP strengthening on serviceability, strength, and failure mechanisms for FRP repaired RC beams. The available literature showed the failure mechanism can move from ductile to very brittle as externally bonded FRPs are added to flexural members. The four failure modes they identified were (1) FRP rupture when its strain exceeds ultimate in the maximum moment zone; (2) Concrete crushing; (3) FRP debonding at the concreteadhesive interface initiated at a flexural crack; (4) Sheartension failure of the concrete at the end of FRP plates resulting in separation of concrete cover from the bottom of the beam soffit.

Failures (1) and (2) are indicative of desirable structural performance and happen after large deflections. Types (3) and (4) are brittle and occur at loads much lower than anticipated using conventional design methods thus provide little advantage.

Arduini and Nanni (1997) divided the parameters that influence the behavior of FRP strengthened RC beams into two groups. The first group consisted of the geometry and properties of the existing member. Testing considered rectangular sections with $(h / b)$ ratios of $0.5,1$, and 4 . Compressive strengths of 20 and $30 \mathrm{MPa}$ were chosen along with a steel reinforcement ratio $(\rho)$ that was $37.5 \%$ of the balanced reinforcement. The shear reinforcement ratio $\left(\rho_{v}\right)$ was held constant at 0.003 . The second group of parameters refers to the repair materials. The FRP thickness $\left(t_{p}\right)$ varied from 0 to $2 \mathrm{~mm}$, while the bonded length of the FRP-toshear span ratio $(p / a)$ varied from 0.60 to 0.95 . Three FRP stiffnesses and corresponding ultimate strains and two adhesives with corresponding ultimate strains were also adopted. With regard to stiffening beams, the reduction of beam deflection under service loads is strongly influenced by the FRP thickness and its related stiffness. Other varying factors were insignificant for reducing the maximum deflection.

For strengthening beams, the outcome of interest was the ratio between ultimate loads of repaired beams compared to unreinforced beams. For the beams reinforced with the highest stiffness FRP, the ultimate strength ratio is strongly influenced by the [ $(p / a)$; bonded length to shear span] ratio. When this ratio was less than 0.65 there was practically no benefit to repairing the beam for strength. When the FRP was $0.1 \mathrm{~mm}$ thick the failure mode was always FRP rupture independent of the $(p / a)$ ratio. With a thickness of $0.5 \mathrm{~mm}$, rupture only occurred for the longest bonded length $(p /$ $a=0.95$ ). All other cases resulted in undesirable sheartension failure mechanisms (concrete cover separation). This failure also indicates that it is no longer possible to increase the flexural capacity by increasing the amount of FRP. Even though the thickness of the epoxy was held constant in their tests, Arduini and Nanni (1997) noted that the vertical normal stress on the interface is directly proportional to the thickness of the adhesive; hence, thinner adhesive layers lower the chances of a concrete-adhesive interface failure.

The second part of the analysis focused on the properties of the existing RC beam. The variables included $(h / b)$ ratios, shear span/effective depth $(a / d)$ ratios, and concrete strength. The parameters that were maintained were the steel reinforcement ratio $(\rho)$, the bonded length-to-shear span ratio $(p /$ $a$ ), the FRP, and the adhesive. Their results indicated that deep beams with $(h / b)$ ratios $>4$ can hardly be stiffened, while sizable gains can be made in square beams and slabs. The best results came from square sections with an (a/ d) ratio $=4.5$.

In general, if a designer is only concerned with deflection reduction and the repaired member is not required to carry more load, then stiffening is always attainable (Arduini and Nanni 1997). For the same thickness, the higher the stiffness, the better the results. However, the failure mode of the repaired beam may become brittle depending on several factors and must be checked. If the designer wants to strengthen an existing member and improve its load carrying capacity at service, the success of such repairs and the selection of FRP stiffness, bonded length, and thickness are all limited by the shear strength of the existing member, the failure mode of the repaired beam, and the deflection under new service loads. For most cases, the bonded length of the 
FRP should be as long as possible to ensure the use of FRP strength and activate other failure mechanisms such as crushing or rupture. Adhesives with high ultimate elongation are beneficial for these cases.

\subsection{Research by Bizindavyi and Neale (1999)}

Bizindavyi and Neale (1999) designed and constructed a testing apparatus and procedure to investigate the interfacial behavior of numerous fiber and resin systems. Based on the test results and corresponding linear elastic analytical model, strain and shear stress distributions and theoretical development lengths were obtained.

The concrete blocks used were $150 \times 150 \times 400 \mathrm{~mm}$ with a mean $f^{\prime}{ }_{c}=42.5 \mathrm{MPa}, f_{c t}=3.5 \mathrm{MPa}$, and an $E$ of $33.5 \mathrm{MPa}$, where $f_{c t}$ is the splitting tensile strength and $E$ is the modulus of elasticity. Both GFRP and CFRP were used in the tests and were prepared with resins as suggested by the manufacturers. The $25 \mathrm{~mm}$ wide composite laminates were bonded to sand blasted and cleaned concrete prisms using a uniform resin thickness of $1-1.2 \mathrm{~mm}$ and various bonded lengths. The specimens were subject to direct shear on the interface by pulling on the FRP strip while the concrete block was held in place with a bearing plate (single lap shear test). The two observed failures were FRP rupture and concrete shearing beneath the bond surface.

The strain distribution profiles show three distinct profile trends corresponding to different regions of the laminate based on level of loading. The first trend is an exponential decrease of strain moving away from the load during initial loading. This strain distribution trend continues until the load becomes large enough to initiate a crack in the concrete. Upon cracking, the distribution becomes bilinear decreasing toward the loaded end. There is steeper decrease in strain toward the loading end with a transition at the point where the strain went to zero in the initial strain trend. During the final stages of loading, the strain distribution becomes approximately linear.

Based on measured strain values, the average shear stress between two gauges and a shear stress distribution were calculated. At loads below cracking, the shear stress distribution mirrored the exponential decay of the strain. However, after cracking occurs near the loaded end, less shear is transferred there and the location of the maximum shear stress shifts toward the unloaded end. The shear force transfer curves also show that there is a load at which shear stress in a region closer to the loading abruptly peaks and then decreases while the shear stress in an adjacent region begins to increase. The decrease represents concrete cracking and the sudden buildup of stress in the next region shows that the load transfer has moved there. This progressive phenomenon occurred until total joint failure.

The load transfer process can be quantified by the strain distribution profiles. According to Bizindavyi and Neale (1999), the distance from the loaded end of the bonded zone to the point where exponential strain decay reaches zero defines the initial transfer length. This is a constant distance for all loads below cracking for a given FRP laminate. Transfer length beyond cracking is also defined as the distance from the edge of the bonded zone to the point where strain becomes zero. This is a function of the relative load. The relation between transfer length and relative load can be approximated as bilinear, with a constant value within service loads (below cracking), followed by a linear increase until failure occurs (Bizindavyi and Neale, 1999).

Bizindavyi and Neale (1999) proposed that the initial transfer length may also be estimated using mean bond strengths where the mean bond strength is defined as the maximum load divided by the bond area. Bizindavyi and Neale (1999) also developed an analytical model to determine the shear stress distribution on the composite-to-concrete bond. It is based on the shear lag theory and only valid in the elastic range. Thus, the analytical results are applicable only for loads less than the initial cracking load, which can be less than $50 \%$ of the failure load. Its application for stiffer laminates, other materials, or field use has not been validated.

\subsection{Research by Chen and Teng (2001)}

In 2001, Chen and Teng (2001) conducted research to discover existing models for FRP strengthening of RC concrete. Some of the earliest, simplest, and thus most often referenced models were examined, including the model by Maeda et al. (1997).

Table 1 from Chen and Teng (2001) presents and compares the ratios of measured to predicted bond strengths of seven models designed to predict ultimate shear strength of the FRP to concrete bonds. The last row in Table 1 was developed by Chen and Teng (2001). The tabulated data show the first four models do not suit the experimental data very well. They largely underestimate the bond strength and have large scatter. Due to the shortcomings of available models, Chen and Teng (2001) felt the need to develop a simple, practical model for design purposes that captured the fundamental bond behavior and provided an accurate prediction of bond strength and effective bond length.

Because of localized bond behavior, Chen and Teng (2001) contend that the assumption commonly made by previous researchers, that bond stress is uniform across a cross section of concrete as well as in the bonded FRP, is invalid. However, it was noted that the width ratio of the bonded plate to the concrete member $\left(b_{p} / b_{c}\right)$, has a significant effect on bond strength. If the FRP plate is narrower than the concrete member, there is a non-uniform stress state at the concrete surface. This may result in higher shear stress in the adhesive at failure that can be attributed to the contribution of concrete outside the bond area.

\subsection{Research by Harmon et al. (2003)}

Harmon et al. (2003) noted that ACI 440's guide for surface bonded FRP explicitly limits strain in the FRP to a value inversely proportional to the FRP's stiffness. The guide does not consider resin properties, concrete strength, and the extent of the flexural cracking. These exclusions are evidence of the lack of a comprehensive bond behavior model. Harmon et al. (2003) developed and presented three models of FRP delamination: (1) ignoring concrete 
Table 1 Ratios of measured to predicted bond strengths.

\begin{tabular}{c|c|c|c|c|c|c|c|c|c}
\hline \multirow{2}{*}{ Model source } & \multicolumn{3}{|c|}{ FRP-to-concrete } & \multicolumn{3}{c|}{ Steel-to-concrete } & \multicolumn{3}{c}{ Both FRP and steel-to-concrete } \\
\cline { 2 - 9 } & Avg. & SD & COV (\%) & Avg. & SD & COV (\%) & Avg. & SD & COV (\%) \\
\hline \hline $\begin{array}{c}\text { Hiroyuki and } \\
\text { Wu (1997) }\end{array}$ & 2.87 & 0.95 & 33 & 3.85 & 1.18 & 31 & 3.24 & 1.09 & 34 \\
\hline $\begin{array}{c}\text { Tanaka } \\
(1996)\end{array}$ & 2.92 & 1.65 & 56 & 5.51 & 5.30 & 96 & 4.02 & 3.96 & 99 \\
\hline $\begin{array}{c}\text { Van Gemert } \\
(1980)\end{array}$ & 2.19 & 1.12 & 51 & 1.64 & 0.57 & 35 & 1.91 & 0.96 & 50 \\
\hline $\begin{array}{c}\text { Chaallal et al. } \\
(1998)\end{array}$ & 1.81 & 0.89 & 49 & 1.68 & 0.70 & 42 & 1.71 & 0.79 & 46 \\
\hline $\begin{array}{c}\text { Khalifa et al. } \\
(1998)\end{array}$ & 1.07 & 0.24 & 23 & 0.76 & 0.26 & 34 & 0.93 & 0.29 & 31 \\
\hline $\begin{array}{c}\text { Neubauer and } \\
\text { Rostasy } \\
(1997)\end{array}$ & 0.82 & 0.15 & 18 & 0.65 & 0.09 & 13 & 0.74 & 0.15 & 20 \\
\hline & 1.05 & 0.18 & 17 & 0.94 & 0.11 & 12 & 1.00 & 0.16 & 16 \\
\hline
\end{tabular}

From Chen and Teng (2001).

flexibility; (2) including concrete flexibility; and (3) for concrete cover separation. In particular, Harmon et al. (2003) proposed that concrete cover separation is due to the maximum shear stress in the bond layer being at the FRP termination point (stress concentration point). The bond stress is due to the force that develops in the FRP as a result of the moment near the termination point. This moment causes an effective strain $\varepsilon_{e}$ in the concrete. The amount of strain will depend on the magnitude of the moment and whether or not the section is cracked based on critical bending moment.

Harmon et al. (2003) conducted four-point bending tests on five beams with conventional steel reinforcement plus surface bonded CFRPs with different fiber and resin systems. Figure 4 shows typical cracks and points where failure was predominantly initiated.

Two fiber systems were selected. The first was a dry sheet with unidirectional fibers with equivalent thickness of $0.165 \mathrm{~mm}$; the sheet was bonded to the concrete substrate via partially cured putty with saturant. The fiber modulus was $227.5 \mathrm{GPa}$ and a single fiber had the strength of $3.8 \mathrm{GPa}$. The second fiber system was a cured laminate with unidirectional fibers. It had a thickness of $0.635 \mathrm{~mm}$ and a modulus of $124.1 \mathrm{GPa}$. Two bond adhesives with different stiffnesses were also considered with layer 1 having a shear modulus of $69 \mathrm{MPa}$ and layer 2's being 6.9 MPa. The beam dimensions were $228.6 \mathrm{~mm}$ deep $\times 152.3 \mathrm{~mm}$ wide and spanned $2133.6 \mathrm{~mm}$. The steel reinforcement consisted of two longitudinal \#4 bars, un-deformed closed \#2 bar stirrups at a spacing $s=101.6 \mathrm{~mm}$, and had $d=203.2 \mathrm{~mm}$. The beams were outfitted with one or two layers of CFRP that had different termination points. Beam 1 was a control beam. Beams 2 and 3 had one layer of CFRP, while Beams 4 and 5 had two layers of CFRP with staggered termination points. Beam 2 had a thin stiff resin layer, Beam 3 had a thicker flexible bond layer, Beam 4 had a thick flexible inner layer with a thin stiff outside layer, and Beam 5 had two thick flexible layers of CFRP.

Beam 1 failed in a ductile manner due to steel yielding. Beam 2, with calculated $L_{e}=5.3 \mathrm{~mm}$ and equal bonded length, failed due to CFRP delamination at crack A (see Fig. 4) with no increase in strength. The third beam (3) had a calculated $L_{e}=107.7 \mathrm{~mm}$ and equal bonded length, and had a $38 \%$ increase in strength before CFRP rupture caused failure. However, Harmon et al. (2003) suggest that because the experimental force $T_{e}$ was close to the maximum allowable, $T_{a}$, the beam would likely have failed due to delamination at crack A had the CFRP been stronger. Concrete cover delamination was not likely since the computed bond stress was only about half of the maximum allowable. Beam 4 failed due to delamination of the outer CFRP at the termination point (crack B; see Fig. 4). Also, because the calculated experimental value of the max bond stress

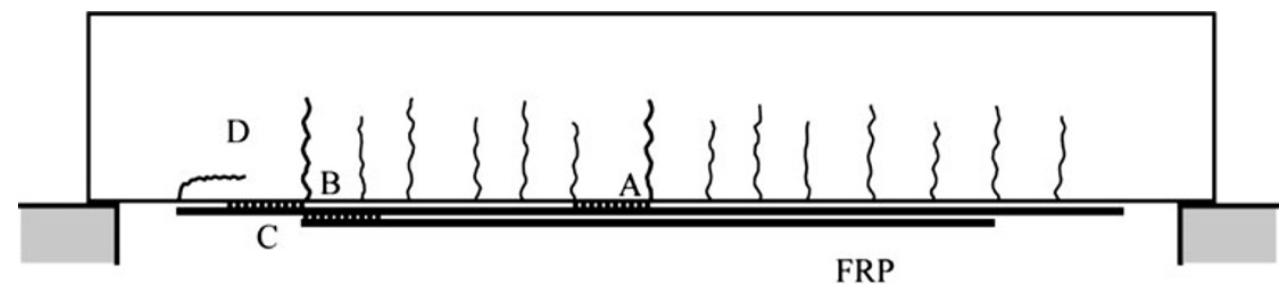

Fig. 4 Typical cracks and locations where FRP debonding failure was predominantly initiated (redrawn from Harmon et al. 2003). 
corresponding to crack D (see Fig. 4) was greater than the allowable value, a concrete cover delamination failure was also eminent, but did not occur. Beam 5 was identical to Beam 4 except that it had a thicker, more flexible outer bond layer. The beam failed in concrete cover delamination as was expected by the bond stress exceeding the allowance. Harmon et al. (2003) attributed the lower failure load to the random nature of concrete. Overall, Harmon et al. (2003) suggest that the phenomenon of measured stress exceeding the allowable stress in the proposed equations shows some inherent conservatism.

These researchers reached several conclusions based on their experiments:

(1) The bond layer's thickness and shear modulus are critical in bond performance. Controlling the thickness is important to prevent premature failure.

(2) The effective length is a quantity proportional to the length of the bond transfer zone. It is the length needed to develop peeling strength if the shear stress is uniformly distributed;

(3) The bond transfer strength is limited by the concrete and is proportional to $\sqrt{ } f_{c}^{\prime}$.

(4) Stiff bond layers are not ideal for beam tests, as predicted by the results of the bond characterization tests and delamination theory.

(5) Additional testing is needed to determine accurate reduction factors.

\subsection{Research by Smith and Teng (2002)}

In 2002, Smith and Teng (2002) conducted a review of existing FRP plate debonding strength models. The research was explicitly concerned with FRP plating of beam soffits under simply supported conditions for simplicity and homogeneous description. However, the conclusions are applicable for any tension face beam plating. Research up until 2002 identified six main failure modes. Smith and Teng (2002) termed these: (a) flexural failure due to FRP rupture; (b) flexural failure due to concrete crushing; (c) shear failure; (d) concrete cover separation; (e) plate end interfacial debonding; and (f) intermediate crack induced interfacial debonding. The first three are not unlike failures in conventional $\mathrm{RC}$ beams, but the second three are unique to beams with a bonded soffit plate. These are widely referred to as premature debonding failures.

The three modes unique to beams strengthened with soffit bonded plates can be broadly classified as those that start at the plate end and propagate toward mid-span, and those that start at an intermediate crack and propagate toward the plate end. Plate end initiated debonding is the far more common failure mode reported, and the research by Smith and Teng (2002) focused on strength models for this failure mode. In plate end debonding failures, separation of the concrete cover, not interfacial debonding, has been more frequently reported. Here, failure initiates at a crack near the end of the FRP plate due to high stresses caused by the abrupt termination of the plate. This crack then progresses up to the level of internal reinforcement and then propagates horizontally resulting in separation of concrete cover. Plate end interfacial debonding is initiated by high interfacial shear stresses that exceed the weakest constituent material's strength (usually concrete). Thus, upon debonding, a thin layer of concrete usually remains attached to the FRP sheet.

\subsection{Research by Yao et al. (2005)}

The lack of a standard test procedure to determine the FRPto-concrete bond strength leaves prediction of debonding failures unclear and subject to limited research data. Yao et al. (2005) adopted the near end supported single shear test to evaluate bond strength. Test variables included bonded length, width ratio between the FRP strip and concrete prism, height of concrete free edge, and offset in load position (load angle). Load angle is known to affect stress distribution but its effect on ultimate load is unknown. The load angle applies to the opening of cracks where there exists a relative vertical displacement between the two sides. The maximum angles tested were $\pm 1.7^{\circ}$. Tensile strengths of the FRPs were determined in accordance with ASTM standards based on nominal thickness before epoxy impregnation. Yao et al. (2005) used Chen and Teng's strength model from 2001 to analyze their test data. This model is developed from a fracture mechanics solution with coefficients regressed from earlier testing and is one of the most commonly used and referenced models. About $75 \%$ of the specimens failed due to concrete failure 1-5 mm below the epoxy-concrete interface. Visible cracking started at the loading-end initiated debonding which propagated towards the far end until complete debonding occurred. The failure surface was jagged and uneven with aggregate clearly showing. Yao et al. (2005) attributed the remainder of the failures to be due to poor surface preparation and a result of the test setup. Yao et al.'s (2005) experimental results support Chen and Teng's bond strength model based on the single shear tests performed.

Yao et al. (2005) found that both positive and negative loading offset have a significant impact on the bond strength when the bonded length is small $(L<95 \mathrm{~mm})$. Loading angle became insignificant for long bonded length. As debonding progresses the angle becomes smaller and thus has less effect. For negative loading angles, this angle is essentially negated because the FRP stays in contact with the concrete even after debonding starts near the loading end. Additionally, negative loading angles result in compressive normal forces that produce friction to help resist the load. Because of the results of the positive loading angle tests, the researchers point to the benefits of sufficiently long bonded lengths for minimizing the effect of relative vertical displacement over a crack.

\section{Bond-Related Analytical Models}

In this section, a review of bond-related analytical models is conducted. It is generally accepted throughout the FRP strengthening research community that there exists an active bond zone, over which the majority of interfacial shear stresses are transferred from the fiber sheet to the concrete. The length of this zone (dependent on FRP width) is known 
Table 2 Effective bond length specified by various FRP guides.

\begin{tabular}{|c|c|c|c|}
\hline Code & Years & Equation & Reference (Origin) \\
\hline $\begin{array}{c}\text { ACI } 440.2 \mathrm{R}-08 \\
\text { (USA) }\end{array}$ & 2008 & $L_{e}=\frac{23300}{\left(n E_{f} t_{f}\right)^{0.58}}$ & $\begin{array}{l}\text { Maeda et al. (1997); } \\
L_{e}=e^{6.134-0.58 \ln \left(E_{f} t_{f}\right)}\end{array}$ \\
\hline $\begin{array}{c}\text { ISIS CSA S806-02 } \\
\text { (Canada) }\end{array}$ & 2002 & $L_{e}=\frac{25350}{\left(E_{f} t_{f}\right)^{0.58}}$ & $\begin{array}{l}\text { Maeda et al. (1997); } \\
L_{e}=e^{6.134-0.58 \ln \left(E_{f} t_{f}\right)}\end{array}$ \\
\hline $\begin{array}{c}\text { FIB B14-Appendix A1 } \\
\text { (Europe) }\end{array}$ & 2001 & $L_{e}=\sqrt{\frac{E_{f} t_{f}}{c_{2} f_{c t m}}}, c_{2}=2$ & $\begin{array}{l}\text { Neubauer and Rostasy (1997); } \\
\qquad L_{e}=\sqrt{\frac{E_{f} t_{f}}{2 f_{c t m}}}\end{array}$ \\
\hline $\begin{array}{c}\text { FIB B14-Appendix A2 } \\
\text { (Europe) }\end{array}$ & 2001 & $L_{e}=c_{2} \sqrt{\frac{E_{f t t_{f}}}{f_{c t m}}}, c_{2}=1.44$ & $\begin{array}{l}\text { Neubauer and Rostasy (1997); } \\
\qquad L_{e}=\sqrt{\frac{E_{f} t_{f}}{2 f_{c t m}}}\end{array}$ \\
\hline $\begin{array}{l}\text { CS TR55 } \\
\text { (UK) }\end{array}$ & 2004 & $L_{e}=0.7 \sqrt{\frac{E_{f} t_{f}}{f_{c t m}}}$ & $\begin{array}{l}\text { Neubauer and Rostasy (1997); } \\
\qquad L_{e}=\sqrt{\frac{E_{f} t_{f}}{2 f_{c t m}}}\end{array}$ \\
\hline $\begin{array}{l}\text { CNR-DT 200/04 } \\
\text { (Italy) }\end{array}$ & 2005 & $L_{e}=\sqrt{\frac{E_{f} t_{f}}{2 f_{c t m}}}$ & $\begin{array}{l}\text { FIB-B14 Apx-A1; } \\
L_{e}=\sqrt{\frac{E_{f} t_{f}}{c_{2} f_{c t m}}} c_{2}=2\end{array}$ \\
\hline $\begin{array}{l}\text { Eurocode } 8-3 \\
\quad \text { (Europe) }\end{array}$ & 2004 & $L_{e}=\sqrt{\frac{E_{f} t_{f}}{4 f_{c t m}}}$ & - \\
\hline $\begin{array}{l}\text { CIDAR } \\
\text { (Australia) }\end{array}$ & 2006 & $L_{e}=\sqrt{\frac{E_{f} t_{f}}{\sqrt{f_{c}^{\prime}}}}$ & $\begin{array}{l}\text { Chen and Teng (2001); } \\
\qquad L_{e}=\sqrt{\frac{E_{f} t_{f}}{\sqrt{f_{c}^{\prime}}}}\end{array}$ \\
\hline- & 2009 & $L_{e}=0.012 t_{f}\left(\frac{E_{f}}{\sqrt{f_{c}^{\prime}}}\right)$ & $\begin{array}{l}\text { Ben Ouezdou et al. (2009); } \\
\qquad L_{e}=0.012 t_{f}\left(\frac{E_{f}}{\sqrt{f_{c}^{\prime}}}\right)\end{array}$ \\
\hline- & 2009 & $L_{e}=\frac{\varepsilon_{f} E_{f} t_{f}}{k \sqrt{f_{c}^{\prime}}}$ & Bakay et al. (2009); $L_{e}=\frac{\varepsilon_{f} E_{f} t_{f}}{k \sqrt{f_{c}^{\prime}}}$ \\
\hline
\end{tabular}

Expanded from the research by Ben Ouezdou et al. (2009).

$E_{f}$ FRP elastic modulus, $L_{e}$ effective bond length, $f_{c}^{\prime}$ concrete strength, $f_{c t m}$ mean tensile concrete strength, $n$ number of FRP layers, $t_{f}$ FRP thickness, $k$ test constant, $\varepsilon_{f}$ FRP strain.

as the effective bond length and is also described as the length beyond which failure load stops increasing, and FRP strain vanishes. Theoretically, bonded lengths beyond this would be inefficient since the full strength of the FRP should have already been exceeded. However, bonded lengths much greater than the effective bond length allow for localized debonding and a shifting of the active zone away from cracked areas, allowing more ductile failures. There has been much research on this issue. Numerous models have been developed based on empirical data and fracture mechanics theories and some of these have been further simplified for design use. However, the effective bond length equations adopted in current codes are very inconsistent. This is because they were developed based on limited experimental data. There remain no accepted analytical models to predict the effective bond length. Table 2, which has been expanded from the research by Ben Ouezdou et al. (2009), summarizes effective bond lengths as specified by FRP guides, governing codes, and independent research.

Table 2 shows that the American ACI code and the Canadian CSA code are contrary to other guidelines' equations for effective length. In these two codes the effective length is inversely proportional to the FRP stiffness, while the rest of the equations have the effective length being proportional to the FRP stiffness.

Many models have been proposed to quantify the bond strength between FRP laminates and concrete (Table 3). The majority of these are based on empirical relations calibrated with empirical data while others were fracture mechanics theories with empirically calibrated parameters. For all cases the stress state simulates a single lap pull-off test on a FRP specimen.

Bakay et al. (2009) gathered current analytical models for predicting the strength of RC beams reinforced with FRP and applied them to an experimental program. These methods included Canadian standard CSA (2002) from ISIS Canada, the simplified shear method (CSA 2002), shear friction, the Blaschko et al. (1998) model, the Plevris et al. (1995) model, and the Hosny et al. (2006) model. The ISIS guidelines do not provide information on how to predict shear capacity of beams with only soffit bonded CFRP. Hence, the addition on the flexural strengthening is assumed to push the beams' failure to a shear failure. Hence the shear capacity of the beams was investigated according to simplified shear and the method of shear friction. The method proposed by Blaschko et al. (1998) is based on Eurocode 2 and explicitly incorporates the amount of externally applied 
Table 3 Bond strength models.

\begin{tabular}{|c|c|}
\hline Model author(s)/source & Model \\
\hline Hiroyuki and $\mathrm{Wu}(1997)$ & $\tau_{u}=0.27 L^{-0.669} \quad P_{u}=\tau_{u} L b_{p}$ \\
\hline Tanaka (1996) and Sato et al. (1996) & $\tau_{u}=6.13-\ln (L) \quad P_{u}=\tau_{u} L b_{p}$ \\
\hline \multirow[t]{2}{*}{ Maeda et al. (1997) } & $\tau_{u}=\left(110.2 \times 10^{-6}\right) E_{f} t$ \\
\hline & $P_{u}=\tau_{u} L_{e} b_{p} \quad L_{e}=e^{6.134-0.58 \ln \left(E_{f} t_{f}\right)}$ \\
\hline \multirow[t]{2}{*}{ Khalifa et al. (1998) } & $\tau_{u}=\left(110.2 \times 10^{-6}\right)\left(f_{c}^{\prime} / 42\right) E_{f} t$ \\
\hline & $P_{u}=\tau_{u} L_{e} b_{p} \quad L_{e}=e^{6.134-0.58 \ln \left(E_{f} t_{f}\right)}$ \\
\hline \multirow[t]{3}{*}{ Sato et al. (1997) and JCI (2003) } & $\tau_{u}=2.68 \times 10^{-5}\left(f_{c}^{\prime}\right)^{0.2} E_{f} t_{f}$ \\
\hline & $P_{u}=\tau_{u} L_{e}\left(b_{p}+7.4\right)$ \\
\hline & $L_{e}=1.89\left(E_{f} t_{f}\right)^{0.4} \quad$ if $L>L_{e}: L=L_{e}$ \\
\hline \multirow[t]{2}{*}{ Iso's Model; JCI (2003) } & $\tau_{u}=0.93\left(f_{c}^{\prime}\right)^{0.44} E_{f} t_{f} \quad P_{u}=\tau_{u} L_{e} b_{p} s$ \\
\hline & $L_{e}=1.25\left(E_{f} t_{f}\right) 0.57 \quad$ if $L>L_{e}: L=L_{e}$ \\
\hline \multirow[t]{2}{*}{ Yang et al. (2007) } & $P_{u}=\left(0.5+0.08 \sqrt{0.01 E_{f} t_{f} / f_{t}}\right) b_{p} L_{e} \tau_{u}$ \\
\hline & $L_{e}=100 \mathrm{~mm} \quad \tau_{u}=0.5 f_{t}$ \\
\hline \multirow[t]{2}{*}{ Chen and Teng (2001) } & $P_{u}=0.427 \beta_{p} \beta_{L} \sqrt{f_{c}^{\prime}} L_{e} \quad L_{e}=\sqrt{\frac{E_{p} t_{p}}{\sqrt{f_{c}^{\prime}}}}$ \\
\hline & $\beta_{p}=\left[\frac{2-\left(b_{p} / b_{c}\right)}{1+\left(b_{p} / b_{c}\right)}\right]^{0.5} \quad \beta_{L}=\left\{\begin{array}{cl}1 & L \geq L_{e} \\
\sin \left(\frac{\pi L}{2 L_{e}}\right) & L<L_{e}\end{array}\right\}$ \\
\hline Täljsten (1994) & $P_{u}=b_{p} \sqrt{\frac{2 G_{f} E_{f} t_{f}}{1+\left(E_{f} t_{f} / E_{c} t_{c}\right)}}$ \\
\hline Yuan and Wu (1999) & $P_{u}=b_{p} \sqrt{\frac{2 G_{f} E_{f} t_{f}}{1+\left(E_{f} t_{f} b_{f} / E_{c} t_{c} b_{c}\right)}}$ \\
\hline \multirow[t]{2}{*}{ Kanakubo (2003) } & $P_{u}=1.1 f_{c}^{\prime 0.2} b_{f} L_{e} \quad\left(L_{b}>L_{e}\right)$ \\
\hline & $L_{e}=0.7 \sqrt{\frac{E_{f} t_{f}}{f_{c}^{\prime 0.2}}}$ \\
\hline
\end{tabular}

(Compiled by the writers of this paper; details such as notations are deferred to the original sources.

FRP in the calculations. The Plevris et al. (1995) method postulates failure is directly proportional to the shear modulus and the areas of steel and FRP reinforcement. The Hosny et al. (2006) method was adopted from Chen and Teng (2001) and slightly altered some of the constraints. The Plevris et al. (1995) method grossly overestimated strengths, while the Hosny et al. (2006) method delivered results that reasonably agreed with the test data while maintaining some conservatism. The comparison of these models can be seen in Fig. 5.

One of the main problems, as argued by Chen et al. (2007), is that the debonding models currently used are based on simple pull-off tests. However, intermediate crack-induced debonding can occur under two scenarios. The first is where there is no significant crack between the free end of the FRP laminate and the crack where debonding initiates. This stress state is similar to the pull-off test. In the second and far more likely scenario, there exist one or more cracks between the debonding initiating crack and the free end. In this case the stress state is totally different from the pull-off tests. Chen et al. (2007) proposed the following equation for the ultimate load on the bonded FRP between two significant cracks:

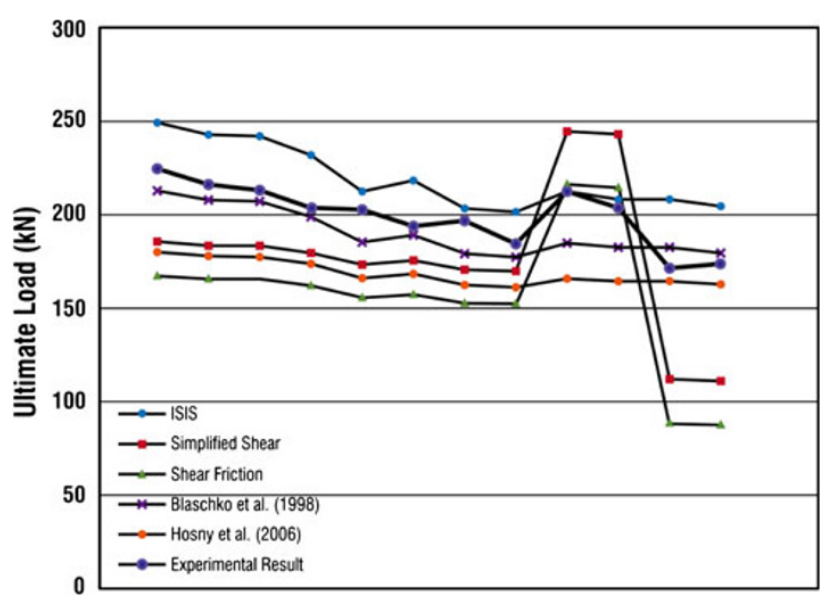

Fig. 5 Comparison of models to predict beam failure loads (data are from Bakay et al. 2009).

$$
P_{u}=b_{p} \frac{\sqrt{2 G_{f} E_{f} t_{f}}}{\sqrt{1-\beta^{2}}} \quad L \geq \frac{1}{\lambda} \arccos \beta
$$




$$
\begin{aligned}
& P_{u}=b_{p} \frac{\sqrt{2 G_{f} E_{f} t_{f}} \sin (\lambda L)}{1-\beta \cos (\lambda L)} \quad L<\frac{1}{\lambda} \arccos \beta \\
& \lambda=\sqrt{\frac{\tau_{f}^{2}}{2 G_{f}}\left(\frac{1}{E_{f} t_{f}}+\frac{b_{p}}{b_{c} E_{c} t_{c}}\right)} \\
& =\frac{\tau_{f}}{\delta_{f} E_{f} t_{f}}\left(1+\frac{E_{f} b_{f} t_{f}}{E_{c} b_{c} t_{c}}\right)
\end{aligned}
$$

where $\tau_{f}$ and $\Delta_{f}$ are the local bond strength and maximum slip of the bonded FRP laminate between the two cracks, respectively; $E_{f}$ and $E_{c}$ are the Young's moduli of the FRP laminate and concrete, respectively; $b_{f}$ and $t_{f}$ are the width and thickness of the FRP laminate, respectively; $b_{p}$ and $L$ are the width and length of the bond area, respectively; $\beta$ is the ratio of forces at the two cracks' locations; $b_{c}$ and $t_{c}$ are the width and thickness of the concrete member, respectively; and $G_{f}$ is the fracture energy defined as the energy under the bond stress-slip curve.

The ACI 440.2R-08 code avoids the issues of determining the governing failure mode that controls the contribution of FRP to strengthened members. Instead, it adopted a model for FRP debonding similar to the one proposed by Chen and Teng (2001) and Teng et al. (2002, 2004). This model simply limits the strain in the FRP laminates, according to strain compatibility, to a value assumed to prevent intermediate crack induced failure. The limiting effective FRP strain value is given by:

$$
\varepsilon_{f d}=0.083 \sqrt{\frac{f_{c}^{\prime}}{n E_{f} t_{f}}} \leq 0.9 \varepsilon_{f u}
$$

where $\varepsilon_{f d}$ is the debonding strain of externally bonded FRP; $n$ is the number of layers of FRP laminate; $f_{c}^{\prime}$ is the concrete compressive strength; and $\varepsilon_{f u}$ is the ultimate rupture strain of externally bonded FRP.

El-Mihilmy and Tedesco (2001) conducted a survey of published results for FRP strengthened beams that failed due to concrete cover separation. They included test data from nine sources encompassing twenty-six uncracked RC beams with a wide range of geometries and constituent reinforcing material properties subject to four point bending tests. ElMihilmy and Tedesco (2001) used analytical models available to predict bond anchorage failure and compared the predictions to the observed failure loads to see how well the models performed. The comparisons demonstrated the need for continuing research and compilation of data on the topic of FRP's bond strength.

\section{Conclusions}

In this paper, previous research programs conducted by other researchers were reviewed in terms of the debonding failure of FRP laminates externally attached to concrete. Failure typically initiates at a crack near the end of the FRP plate due to high stresses caused by the abrupt termination of the plate. This crack then progresses up to the level of internal reinforcement and then propagates horizontally, resulting in separation of concrete cover. Finally, plate-end interfacial debonding is initiated by high interfacial shear stresses that exceed the weakest constituent material's strength (usually concrete). Based on the review, the following key points are re-emphasized:

(1) Since the failure mode of the FRP-concrete interface involves shearing the concrete directly below the bond, the ultimate strength or bond transfer strength is proportional to $f_{c}^{\prime}$ or $\sqrt{f_{c}^{\prime}}$.

(2) Surface preparation greatly influences the ultimate bond strength. Roughening and cleaning the composite plate also improves bonding.

(3) The use of more ductile adhesives leads to weaker bonds but larger failure strains.

(4) The strain distribution in the composite decreases linearly along the bond length, only near the ultimate stage, indicating the force transfer is mostly uniform along the length.

(5) If the FRP plate is narrower than the concrete member, there is a non-uniform stress state at the concrete surface, which may result in higher shear stress in the adhesive at failure that can be attributed to the contribution of concrete outside the bond area.

(6) There is a bond development length beyond which the load at failure cannot be increased; however, it is recommended that the bonded length of the FRP be as long as possible, along with the use of adhesives with high ultimate elongation, to promote the use of FRP strength and activate other failure mechanisms such as crushing or rupture.

(7) The reduction of beam deflection under service loads is strongly influenced by the FRP thickness and its related stiffness. Other varying factors were insignificant for reducing the maximum deflection.

(8) The thinner adhesive layers lower the chances of a concrete-adhesive interface failure; thus, stiff bond layers are not ideal.

(9) It is expected that debonding of the FRP would be delayed or prevented by adding transverse straps (Fig. 6). The transverse straps placed close to the high moment region within the shear span would be more effective than those near the end of the span.

Based on the review of previously developed models, the inconsistency, uncertainty and inaccuracy of some of the available models exist in the prediction of effective bond length and maximum load capacity of RC beams strengthened with FRP. The behavior of FRP-rehabilitated reinforced concrete structures is still a developing technology that has yet to be accurately and conveniently modeled in most situations. One of the areas lacking an overall understanding is the interface and bond between the FRP laminates and the concrete substrate. The lack of understanding on the bond and subsequent composite action between the FRP and the concrete has led to many premature failures of FRP- 


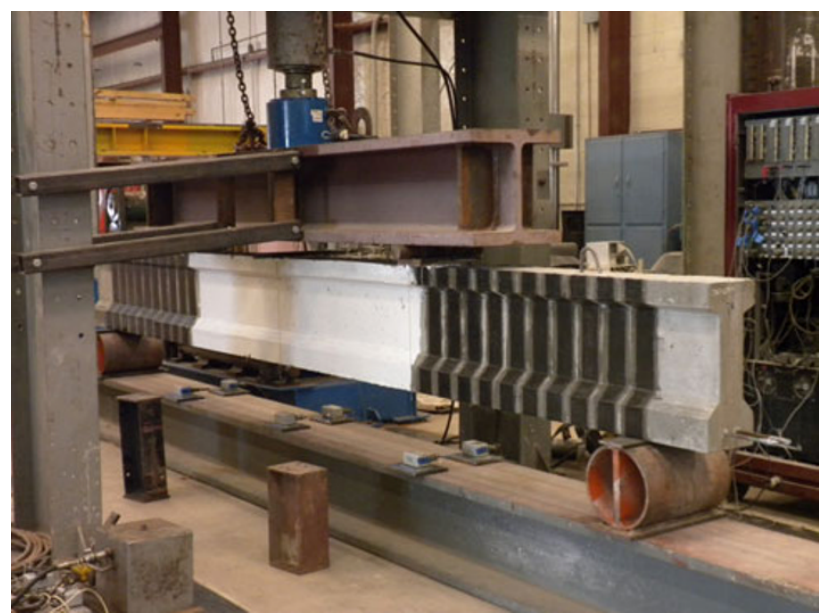

Fig. 6 Transverse straps of FRP placed within shear span (photo by T. Kang).

strengthened concrete members. It is important for research to continue in order to grow the database from which results may be drawn. Continued research with cooperation between different researchers and agencies worldwide is also important for developing accurate, reliable, and straight forward design models.

\section{Acknowledgments}

The work presented in this paper was supported by the National Research Foundation of Korea (NRF) grant funded by the Korea government (MEST) (No. 2012005905). The views expressed are those of the authors, and do not necessarily represent those of the sponsor.

\section{Open Access}

This article is distributed under the terms of the Creative Commons Attribution License which permits any use, distribution, and reproduction in any medium, provided the original author(s) and the source are credited.

\section{References}

ACI Committee 440. (2008). Guide for the design and construction of externally bonded FRP systems for strengthening concrete structures (ACI 440.2R-08), July 2008. Farmington Hills, MI: American Concrete Institute.

Arduini, M., \& Nanni, A. (1997). Parametric study of beams with externally bonded FRP reinforcement. ACI Structural Journal, 94(5), 493-501.

Arduini, M., Tommaso, A. D., \& Nanni, A. (1997). Brittle failure in FRP plate and sheet bonded beams. ACI Structural Journal, 94(4), 363-370.

Bakay, R., Sayed-Ahmed, E. Y., \& Shrive, N. G. (2009). Interfacial debonding failure for reinforced concrete beams strengthened with carbon-fiber-reinforced polymer strips. Canadian Journal of Civil Engineering, 36, 103-121.

Ben Ouezdou, M., Belarbi, A., \& Bae, S.-W. (2009). Effective bond length of FRP sheets externally bonded to concrete. International Journal of Concrete Structures and Materials, 3(2), 127-131.

Bizindavyi, L., \& Neale, K. W. (1999). Transfer lengths and bond strengths for composites bonded to concrete. ASCE Journal of Composites for Construction, 3(4), 153-160.

Blaschko, M., Niedermeier, R., \& Zilch, K. (1998). Bond failure modes of flexural members strengthened with FRP. In Proceedings of the Second International Conference on Composites in Infrastructure (Vol. 1, pp. 315-327), Tucson, Arizona, USA.

Buyukozturk, O., Gunes, O., \& Karaca, E. (2004). Progress on understanding debonding problems in reinforced concrete and steel members strengthened using FRP composites. Construction and Building Materials, 18, 9-19.

Canadian Standards Association. (2002). Design and construction of building components with fiber-reinforced polymers, CSA S806-02. Rexdale, Ontario.

Chajes, M. J., Finch, W. W, Jr, Januszke, T. F., \& Thomson, T. A, Jr. (1996). Bond and force transfer of composite material plates bonded to concrete. ACI Structural Journal, 93(2), 208-217.

Chaallal, O., Nollet, M.-J., \& Perraton, D. (1998). Strengthening of reinforced concrete beams with externally bonded fiber-reinforced-plastic-plates: Design guidelines for shear and flexure. Canadian Journal of Civil Engineering, 25, 692-704.

Chen, J. F., \& Teng, J. G. (2001). Anchorage strength models for FRP and steel plates bonded to concrete. ASCE Journal of Structural Engineering, 127(7), 784-791.

Chen, J. F., Yuan, H., \& Teng, J. G. (2007). Debonding failure along a softening FRP-to-concrete interface between two adjacent cracks in concrete members. Engineering Structures, 29, 259-270.

CIDAR. (2006). Design guideline for RC structures retrofitted with FRP and metal plates: Beams and slabs. Draft 3, Submitted to Standards Australia, CIDAR/CBIR, Australia, 2006.

El-Mihilmy, M. T., \& Tedesco, J. W. (2001). Prediction of anchorage failure for reinforced concrete beams strengthened with fiber-reinforced polymer plates. ACI Structural Journal, 98(3), 301-314.

Eurocode 8-3. (2004). Design of structures for earthquake resistance; part 3: Assessment and retrofitting of buildings. European Standard, EN 1998-3, Brussels, Belgium.

FIB Task Group 9.3. (2001). Externally bonded FRP reinforcement for RC structures. Technical report, Fib bulletin 14, CEB-FIP, Lausanne, Switzerland.

Harmon, T. G., Kim, Y. J., Kardos, J., Johnson, T., \& Stark, A. (2003). Bond of surface-mounted fiber-reinforced polymer reinforcement for concrete structures. ACI Structural Journal, 100(5), 557-564.

Hiroyuki, Y., \& Wu, Z. (1997). Analysis of debonding fracture properties of cfs strengthened member subject to tension. In Proceedings of the third international symposium 
(FRPRCS-3), non-metallic (FRP) reinforcement for concrete structures (pp. 287-294). Sapporo, Japan: Japan Concrete Institute.

Hosny, A. A., Sayed-Ahmed, Y., Abdelrahamm, A. A., \& Alhlaby, N. A. (2006). Strengthening precast-prestressed hollow core slabs to resist negative moments using CFRP strips: An experimental investigation and a critical review of CSA 806-02. Canadian Journal of Civil Engineering, 33(8), 955-967.

ISIS Canada. (2001). Strengthening reinforced concrete structures with externally-bonded fibre reinforced polymers (FRPs). ISIS Design Manual No. 4, Intelligent Sensing for Innovative Structures, Winnipeg, Canada.

Italian Society Research Society. (2004). Instructions for the design, execution and control of strengthening measures through fibre-reinforced composites. CNR-DT 200/04. Rome, Italy.

Japan Concrete Institute. (2003). International symposium on latest achievement of technology and research on retrofitting concrete structures. Proceedings and technical report on JCI Technical Committee, Sapporo, Japan, 2003 (in Japanese).

Kanakubo, T., Furuta, T., \& Fukuyama, H. (2003). Bond strength between fiber-reinforced polymer laminates and concrete. In Proceedings of 6th international RILEM symposium on non-metallic (FRP) reinforcement for concrete structures (FRPRCS-6) (pp. 134-143). Singapore: World Scientific.

Khalifa, A., Gold, W. J., Nanni, A., \& Aziz, A. (1998). Contribution of externally bonded FRP to shear capacity of RC flexural members. ASCE Journal of Composites for Construction, 2(4), 195-203.

Maeda, T., Asano, Y., Sato, T., Ueda, T., \& Kakuta, Y. (1997). A study on bond mechanism of carbon sheet. In Proceedings of the third international symposium (FRPRCS-3), nonmetallic (FRP) reinforcement for concrete structures (Vol. 1, pp. 279-286). Sapporo, Japan.

Neubauer, U., \& Rostásy, F. S. (1997). Design aspects of concrete structures strengthened with externally bonded CFRPplates. In Proceeding of the seventh international conference on structural faults and repair (Vol. 2, pp. 109-118). Scotland, Edinburgh: ECS.

Plevris, N., Triantafillou, T. C., \& Veneziano, D. (1995). Reliability of RC members strengthened with CFRP laminates. ASCE Journal of Structural Engineering, 121(7), 1037-1044.

Sato, Y., Kimura, K., \& Kobatake, Y. (1997). Bond behavior between CFRP sheet and concrete (part 1). Journal of
Structure and Construction Engineering of AIJ, 500, 75-82. (in Japanese).

Sato, Y., Ueda, T., Kakuta, Y., \& Tanaka, T. (1996). Shear reinforcing effect of carbon fibre sheet attached to side of reinforced concrete beams. In M. M. El-Badry (Ed.), Proceedings of 2 nd international conference on advanced composite materials in bridges and structures (pp. 621-627). Montreal: Canadian Society for Civil Engineering.

Smith, S. T., \& Teng, J. G. (2002). FRP-strengthened RC beams. II: Assessment of debonding strength models. Engineering Structures, 24, 397-417.

Täljsten, B. (1994). Plate bonding: Strengthening of existing concrete structures with epoxy bonded plates of steel or fibre reinforced plastics. Doctoral thesis, University of Technology, Sweden.

Tanaka, T. (1996). Shear resisting mechanism of reinforced concrete beams with CFS as shear reinforcement. Graduation Thesis, Hokkaido University, Japan.

Teng, J. G., Chen, J. F., Smith, S. T., \& Lam, L. (2002). FRP strengthened RC structures. West Sussex: Wiley.

Teng, J. G., Lu, X. Z., Ye, L. P., \& Jiang, J. J. (2004). Recent research on intermediate crack induced debonding in FRPstrengthened RC beams. In Proceedings of the 4th international conference on advanced composite materials in bridges and structures. Calgary, Alberta, Canada.

The Concrete Society. (2004). Design guidance for strengthening concrete structures using fibre composites materials (Technical report no. 55, 2nd edn.). Report of a Concrete Society Committee. Berkshire, UK: Concrete Society, CSTR-55-UK.

Van Gemert, D. (1980). Force transfer in epoxy-bonded steelconcrete joints. International Journal of Adhesion and Adhesives, 1, 67-72.

Yang, D.-S., Hong, S.-N., \& Park, S.-K. (2007). Experimental observation on bond slip behavior between concrete and CFRP Plate. International Journal of Concrete Structures and Materials, 1(1), 37-43.

Yao, J., Teng, J. G., \& Chen, J. F. (2005). Experimental study on FRP-to-concrete bonded joints. Composites: Part B, 36, 99-113.

Yuan, H., \& Wu, Z. (1999). Interfacial fracture theory in structures strengthened with composite of continuous fiber. In Proceedings of symposium of China and Japan: Science and technology of 21st century (pp. 142-155) Tokyo, Japan. 